\title{
Association of monocyte-to-high density lipoprotein ratio with arterial stiffness in patients with diabetes
}

${\text { Dyah Samti Mayasari }{ }^{*} \mathbb{B} \text {, Nahar Taufiq }}^{1,2}$ and Hariadi Hariawan ${ }^{1,2}$

\begin{abstract}
Background: Previous studies proposed that chronic inflammation in diabetes has a role in abnormal collagen production and elastin degradation, which promotes arterial stiffness. Monocyte-to-High Density Lipoprotein cholesterol ratio (MHR) is a simple measurement associated with inflammation and oxidative stress. However, little is known about the relationship of MHR with arterial stiffness. This study aimed to determine the association of MHR with arterial stiffness in patients with diabetes.

Methods: A total of 81 patients with type 2 diabetes mellitus were enrolled in a cross-sectional study. Arterial stiffness factor in this study was Cardio Ankle Vascular Index (CAVI). We analyzed complete blood count and lipid profile in all participants, then performed statistical analysis to determine the relationship between MHR and CAVI. Receiver operating characteristic (ROC) analysis was used to estimate the cut-off values of MHR to predict CAVI $\geq 9$.
\end{abstract}

Results: Median of MHR in this study was 11.91 with the mean of CAVI was $8.13 \pm 0.93$. Spearman correlation analysis revealed a significant positive correlation between MHR and CAVI $(\rho=0.239, p=0.031)$. Multivariate analysis showed the independent association of MHR to arterial stiffness ( $\beta=0.361,95 \% \mathrm{Cl} 0.023-0.093)$ and to CAVI $\geq 9$ (OR 1.181, $95 \% \mathrm{Cl} 1.047-1.332)$. The cut-off values of MHR for predicting CAVI $\geq 9$ were identified as $\geq 13$ (OR $3.289,95 \% \mathrm{Cl}$ 1.036-10.441).

Conclusion: MHR is associated with CAVI in patients with diabetes, irrespective of various potential confounders.

Keywords: Monocyte-to-HDL ratio, Cardio ankle vascular index, Arterial stiffness, Inflammation biomarkers, Diabetes

\section{Background}

Patients with diabetes mellitus (DM) are at higher risk of vascular complications. The dysfunction of endothelial and smooth muscle cells causes vascular homeostasis alteration, becoming a pro-inflammatory/ thrombotic condition. Hyperglycemia, gather with other risk factors such as arterial hypertension and dyslipidemia, increases the risk of macro and microvascular

\footnotetext{
*Correspondence: dyah.samti.m@ugm.ac.id

${ }^{1}$ Department of Cardiology and Vascular Medicine, Public Health and Nursing, Faculty of Medicine, Universitas Gadjah Mada, Jl Farmako No 1, Sekip, Yogyakarta 55281, Indonesia

Full list of author information is available at the end of the article
}

diabetic complications $[1,2]$. Type 2 DM, especially the uncontrolled condition, associated with a risk of arterial stiffness in the future life [3]. Diabetes mellitus associated with aortic stiffness was found comparable to over 6 years of nonsmoker without diabetes [4].

Arterial stiffness is the result of complex interactions of cellular and structural elements of vessel walls. Imbalance of vessel stability, especially through inflammation stimulation, causes an excess production of abnormal collagen and elastin diminution [5]. Arterial stiffness is found as an independent predictor of cardiovascular events [6]. The multicentre observational Rebound study showed that the increasing of arterial stiffness predict the 


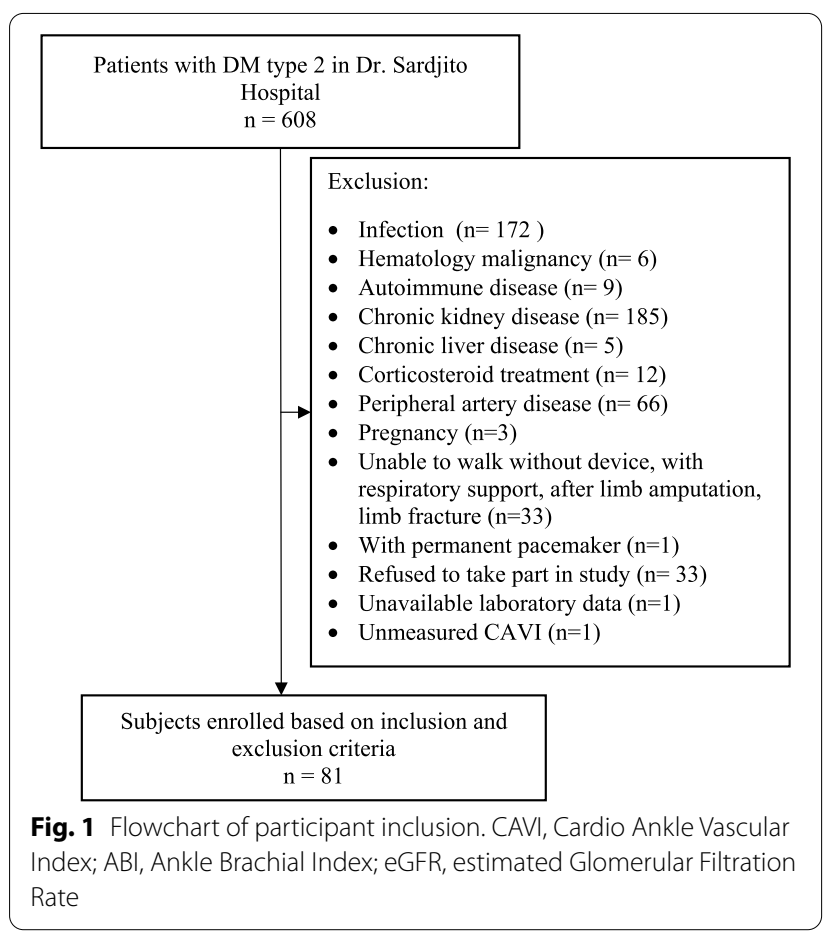

risk of all-cause and cardiovascular mortality in type 2 diabetes [7]. Another study demonstrated the association of arterial stiffness with subclinical myocardial injury in patients with type $2 \mathrm{DM}[8]$. Therefore, the assessment of arterial stiffness in patients with type $2 \mathrm{DM}$ is important to decide the best management to prevent future cardiovascular events.

Inflammation has a significant role in major arterial stiffness. Macrophages and monocytes produce proinflammatory and pro-oxidant cytokines in areas with inflammation. The increasing of monocyte count occurs in the worst cardiovascular diseases [9]. High Density Lipoprotein (HDL) has already been known as a particle that protects endothelial cells [10]. HDL stimulates Nitrite oxide (NO) release and increases the expression of eNOS (endothelial NO synthase). HDL suppresses the expression of adhesion molecules, such as vascular cell adhesion molecule 1 , and inhibits the adhesion of white blood cells. HDL also has antithrombotic effect since it reduces the expression of tissue factor in endothelial cells exposed to cytokines and reduces platelet activation [11]. Monocyte to HDL ratio (MHR) is a new biomarker related to inflammation and oxidative stress, shown as the increasing of monocyte count in proportion to the reducing of HDL cholesterol level. Previous study showed that MHR positively correlates with diabetes mellitus and significantly associated to resistant hypertension in chronic kidney disease patients [12]. The increasing of MHR has also known as a biomarker of diabetic nephropathy [13].
However, the role of MHR in arterial stiffness of patients with diabetes is still not well-explored. The aim of this study is to observe the association of MHR with arterial stiffness in patients with diabetes.

\section{Methods \\ Research design and subjects}

The research design was an observational study with cross-sectional methods. We conducted a consecutive sampling to enroll patients who were diagnosed with DM. The study was conducted in the outpatient clinic of Endocrinology Clinic and Cardiology Clinic of Dr. Sardjito General Hospital, Yogyakarta, Indonesia. The research was performed from April to July 2020. The inclusion criteria of this study were patients who were diagnosed as DM type 2 and willing to enroll in this study. Patients with infection, haematology malignancy, autoimmune disease, on oral or intravenous corticosteroid treatment, chronic kidney disease (estimated Glomerular Filtration Rate $($ eGFR $)<60 \mathrm{~mL} / \mathrm{min} / 1.73 \mathrm{~m}^{2}$ ), chronic liver disease, peripheral artery disease (Ankle Brachial Index $(A B I)<0.9)$, pregnancy, with permanent pacemaker, and patients who were unable to be examined (unable to walk without device, with respiratory support, after limb amputation, and/or limb fracture) were excluded from the study. This study was approved by the Medical and Health Research Ethics Committee (MHREC) Faculty of Medicine, Public Health and Nursing, Universitas Gadjah Mada-Dr. Sardjito General Hospital, Indonesia.

\section{Clinical assessments}

Medical history was collected by interviewing the patients and obtaining the medical record of each patient. Diabetes mellitus was diagnosed as fasting glucose plasm $\geq 126 \mathrm{mg} / \mathrm{dL}$, or plasm glucose $\geq 200 \mathrm{mg} / \mathrm{dL}$ $2 \mathrm{~h}$ after oral glucose tolerance test with $75 \mathrm{mg}$ glucose load, or random plasm glucose $\geq 200 \mathrm{mg} / \mathrm{dL}$ with the classical symptom, or HbA1c $\geq 6.5 \%$. Uncontrolled DM was defined as $\mathrm{HbA1c} \geq 7 \%$ from peripheral blood measurement. Smoking status, DM duration, and statin treatment duration were identified by anamnesis. Smoking status was classified as an active smoker, former smoker, and non-smoker [14]. DM duration was calculated from the first time patient diagnosed with DM. Body mass index (BMI) was calculated by body weight/(height ${ }^{2}$ ). Systolic blood pressure and pulse pressure were measured using the same device for all patients. Hypertension was defined as average blood pressure more than 140/90 (after three times measurements), or in the treatment of antihypertensive. Treatments were collected from the medical records. Statin treatment was classified as a lowintensity statin, moderate-intensity statin, high-intensity 
Table 1 Baseline characteristics of the subject participants

\begin{tabular}{|c|c|}
\hline Variable $(n=83)$ & Value \\
\hline Age, y.o & $55(49-60)$ \\
\hline \multicolumn{2}{|l|}{ Sex } \\
\hline Male, n (\%) & $45(55.6)$ \\
\hline Female, n (\%) & $36(44.4)$ \\
\hline \multicolumn{2}{|l|}{ Smoking, n (\%) } \\
\hline Active smoker, n (\%) & $6(7.4)$ \\
\hline Former smoker, n (\%) & $24(29.6)$ \\
\hline Never smoker, n (\%) & $51(63)$ \\
\hline DM duration, years & $6(3-11)$ \\
\hline History of hypertension, n (\%) & $52(64.2)$ \\
\hline History of dyslipidemia, n (\%) & $48(59.3)$ \\
\hline DM complication: & $44(54.3)$ \\
\hline Coronary artery disease, n (\%) & $28(34.6)$ \\
\hline Chronic heart failure, n (\%) & $7(8.6)$ \\
\hline Stroke, n (\%) & $9(11.1)$ \\
\hline Diabetic retinopathy, n (\%) & $13(16)$ \\
\hline Body mass index, $\mathrm{kg} / \mathrm{m}^{2}$ & $24.78 \pm 3.79$ \\
\hline Systolic blood pressure, mmHg & $141.12 \pm 20.49$ \\
\hline Pulse pressure, $\mathrm{mmHg}$ & $58.36 \pm 15.36$ \\
\hline \multicolumn{2}{|l|}{ Treatment parameter } \\
\hline Statin, n (\%) & $48(59.3)$ \\
\hline Low intensity statin, n (\%) & $17(21)$ \\
\hline Moderate intensity statin, n (\%) & $28(34.6)$ \\
\hline High intensity statin, n (\%) & $3(3.7)$ \\
\hline High intensity statin + ezetimibe, $n$ (\%) & 0 \\
\hline Statin duration, years & $0.083(0-1.5)$ \\
\hline ACE inhibitor/ARB, n (\%) & $46(56.8)$ \\
\hline Vitamin, $n(\%)$ & $40(49.4)$ \\
\hline Antidiabetic drugs: & 79 (97.5) \\
\hline Oral anti diabetic drugs, n (\%) & $35(43.2)$ \\
\hline Insulin, n (\%) & $27(33.3)$ \\
\hline Combination of oral and insulin, $n(\%)$ & $17(21)$ \\
\hline Nitrate, $n(\%)$ & $11(13.6)$ \\
\hline NSAID, n (\%) & $32(38.3)$ \\
\hline \multicolumn{2}{|l|}{ Artery examination parameter } \\
\hline$A B \mid$ & $1.05 \pm 0.076$ \\
\hline CAVI & $8.14 \pm 0.93$ \\
\hline \multicolumn{2}{|l|}{ Laboratory parameter } \\
\hline Leucocyte count, $\times 10^{3} / \mu \mathrm{L}$ & $8.06 \pm 2.05$ \\
\hline Monocyte count, $\times 10^{3} / \mu \mathrm{L}$ & $0.53(0.46-0.64)$ \\
\hline Fasting blood glucose, mg/dL & $151(113-210)$ \\
\hline $\mathrm{HDL}$ cholesterol, mg/dL & $43(38-50)$ \\
\hline LDL cholesterol, mg/dL & $133.75 \pm 41.68$ \\
\hline LDL $\geq 160$ mg/dL, n (\%) & $23(28.4)$ \\
\hline $\mathrm{HbA1c} \%$ & $8.56 \pm 1.98$ \\
\hline $\mathrm{HbA1c} \geq 7 \%, \mathrm{n}(\%)$ & $58(71.6)$ \\
\hline Monocyte to HDL ratio (MHR) & $12.56(9.62-15.53)$ \\
\hline Creatinine, $\mathrm{mg} / \mathrm{dL}$ & $0.89 \pm 0.2$ \\
\hline Estimated GFR, mL/min/1.73 m² & $84.35(71.51-101.09)$ \\
\hline
\end{tabular}

Table 1 (continued)

Data were shown as mean \pm SD for normal distribution data, median (interquartile range) for non-normal distribution data and number (percentage) for categorical data

ABI: Ankle brachial index, ACE: angiotensin converting enzyme, ARB: angiotensin receptor blocker, CAVI: cardio ankle vascular index, DM: diabetes mellitus, GFR: glomerular filtration rate, HbA1c: hemoglobin a1c, HDL: high density lipoprotein, LDL: low density lipoprotein, NSAID: non steroid anti-inflammatory drugs, SD: standard deviation

statin, and high-intensity statin added by ezetimibe[15]. DM complications were identified from the diagnosis of coronary artery disease, stroke, chronic heart failure, or diabetic retinopathy.

\section{CAVI and laboratory data collection}

CAVI was measured by Vascular Screening System VaSera VS-1500 (Fukuda Denshi, Japan). The patient was in supine position at least $10 \mathrm{~min}$ before examination. Arm and ankle cuff were wrapped and microphone for phonocardiograph was seated on 2nd intercostal space of sternum. ABI and CAVI results were shown automatically in the VaSera monitor. ABI was calculated as the lowest $\mathrm{ABI}$ measured from right and left ankle. CAVI was measured as mean of right and left CAVI. The antecubital vein blood samples were taken after fasting for at least $8 \mathrm{~h}$, and analyzed in the central hospital laboratory. Complete leucocyte count, HDL and LDL cholesterol level, fasting blood glucose, HbA1c and creatinine were measured. Monocyte-to-HDL ratio (MHR) was calculated manually by dividing monocyte count and HDL cholesterol level. Blood examinations were done in the same day as CAVI examination. The primary outcome of this study was the association between MHR and arterial stiffness, as measured by CAVI. The secondary endpoint was the optimal cut-off value of MHR to predict CAVI $\geq 9$, as as the predictive cut-off for the future cardiovascular events in asymptomatic patients with type 2 diabetes [16].

\section{Statistical analysis}

Statistical analysis was performed using SPSS IBM 23 version (International Business Machine Corp., Chicago) for Windows. The estimation of minimal sample size was 81 patients with the statistical power of $75 \%$. The estimated sample size was calculated for the correlation of MHR with arterial stiffness. Normality test was analyzed by Kolmogorov Smirnov test, in which $p>0.05$ was considered normal distribution data and shown as mean \pm standard deviation (SD), while nonnormal distribution data were shown as median with interquartile range (IQR). Categorical data were shown as number (percentage). Correlations between two numeric data were analyzed by Spearman correlation 

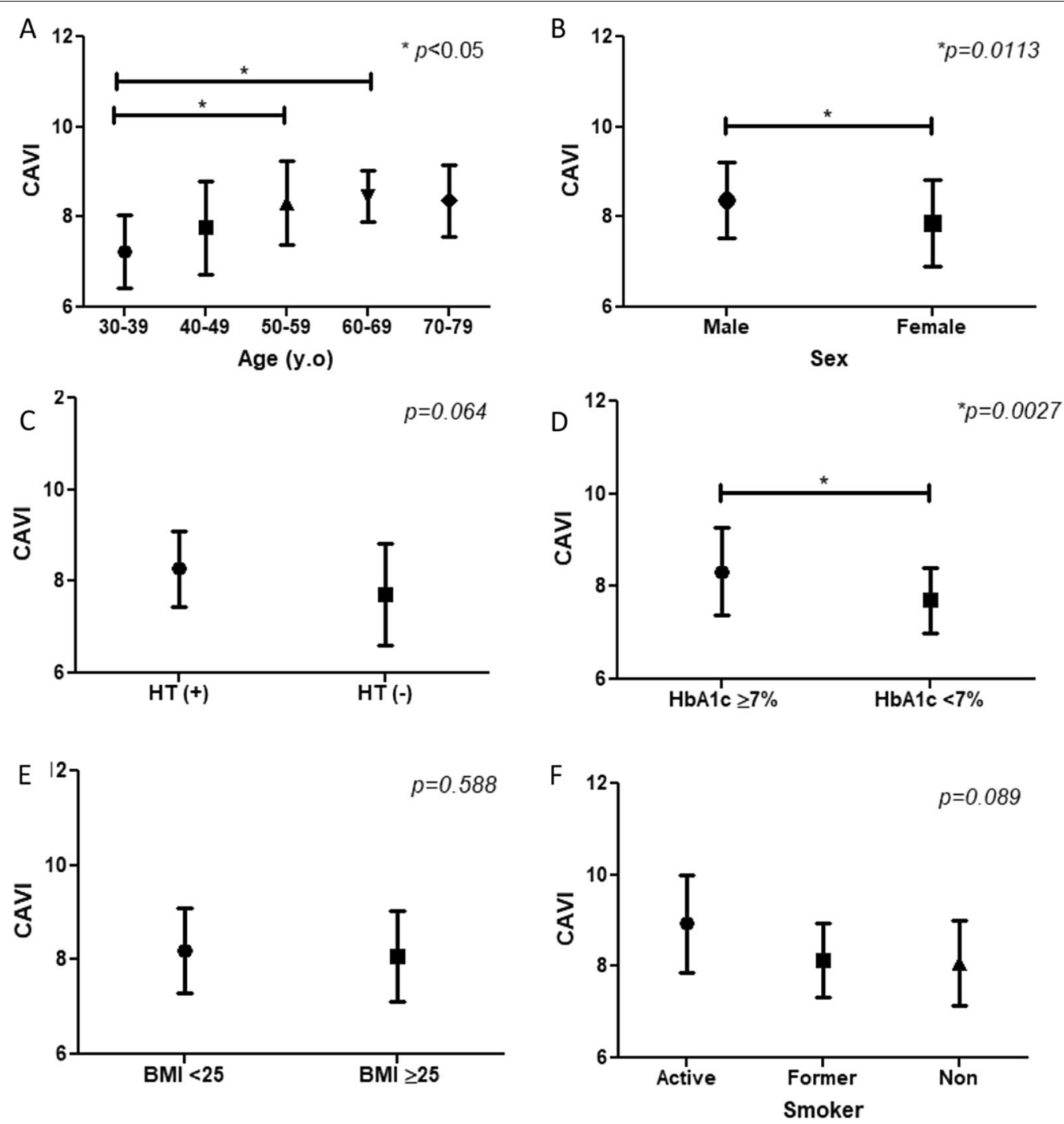

Fig.2 Comparison of mean CAVI according to the increasing of age (A), sex (B), hypertension status (C), uncontrolled diabetes (D), BMI (E), and smoker (F). CAVI, Cardio Ankle Vascular Index; BMI, Body Mass Index

tests for non-normal distribution data. The difference of CAVI mean with each categorical variable was analyzed by independent t-tests. The difference of MHR distribution with each categorical variable was analyzed by Mann Whitney test. Univariate linear regression was assessed and multivariate linear regression was conducted for the variables that have significance $\mathrm{p}<0.25$ in univariate analysis, for the assessment of association of variables with arterial stiffness. Result of $p<0.05$ in multivariate linear regression was considered as statistically significant. Logistic regression was performed in order to observe the association of MHR with CAVI $\geq 9$. The receiver operating characteristic (ROC) curve was used to demonstrate the sensitivity, specificity, and cut-off value of MHR.

\section{Results}

From April to July 2020, 608 patients with diabetes presented at Dr. Sardjito General Hospital Yogyakarta, Indonesia. Five hundred and twenty seven patients were excluded based on the above mentioned criteria, and 81 subjects was enrolled in this study (Fig. 1).

This study consisted of patients with DM with the age range from 30 to 77 years old with median 55 years old. Among the subjects, 45 patients were male (55.6\%). 
A

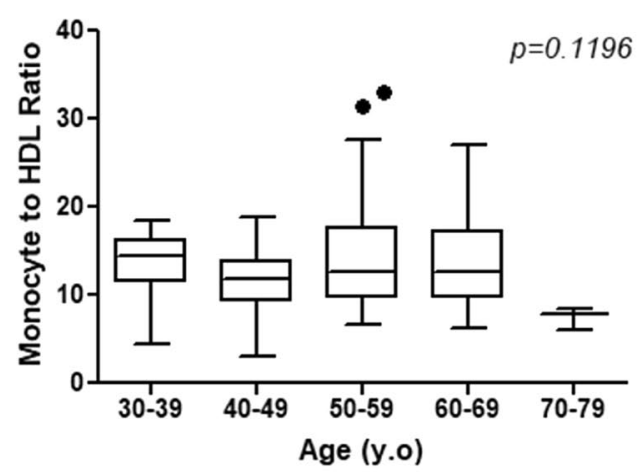

C

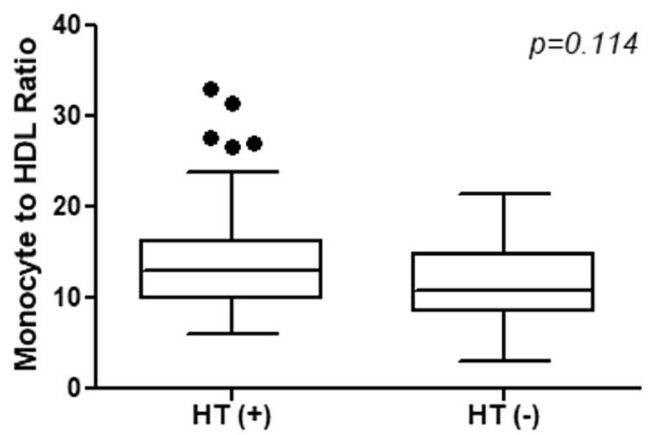

E

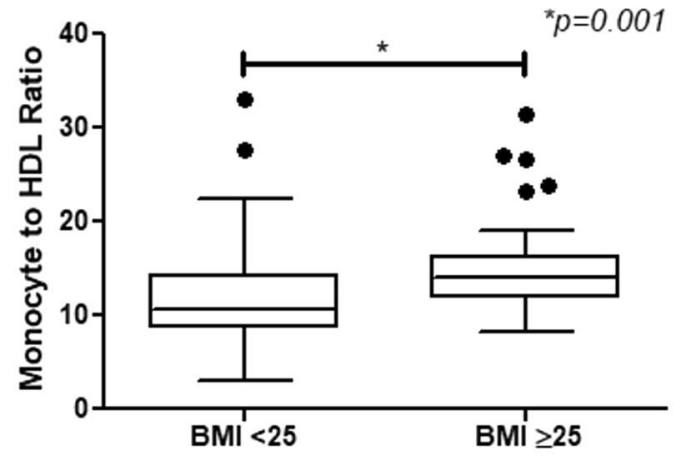

B

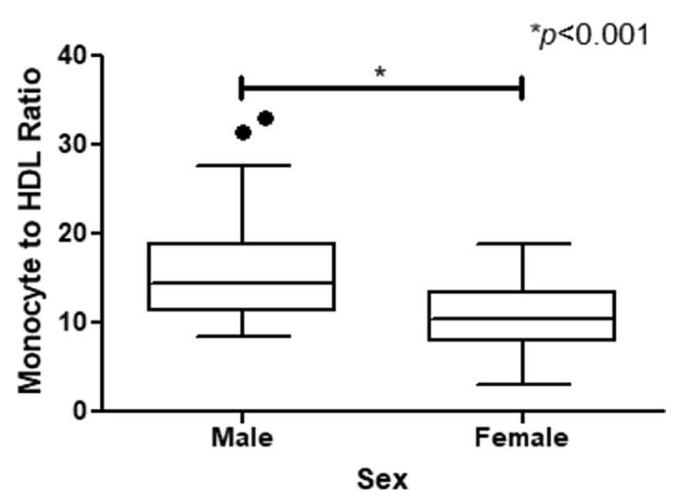

D

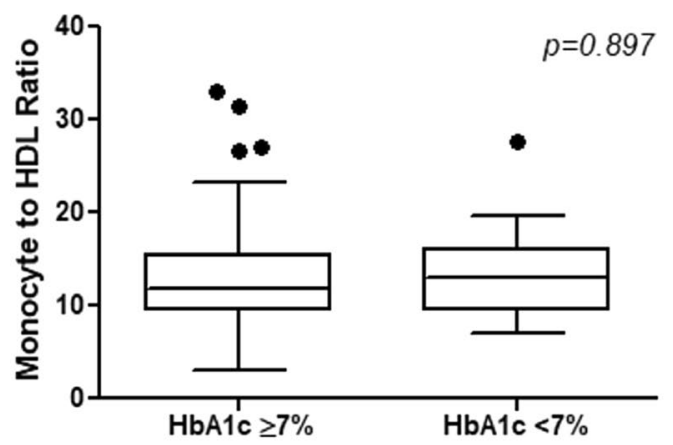

$\mathrm{F}$

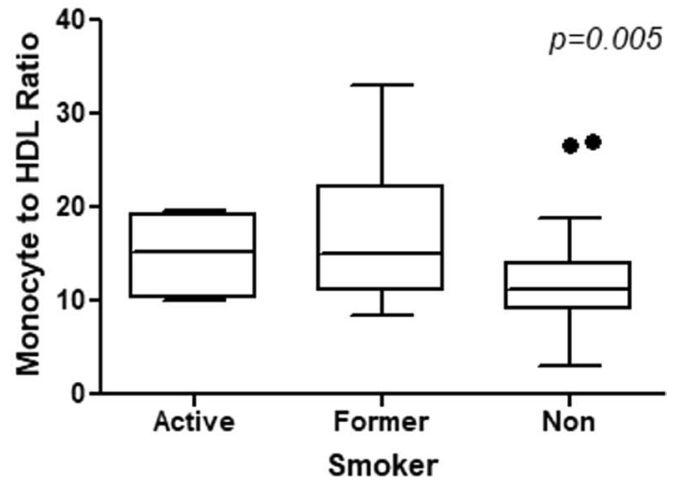

Fig. 3 Comparison of monocyte-to-HDL ratio distribution according to the increasing of age (A), sex (B), hypertension status (C), uncontrolled diabetes (D), BMI (E), and smoker (F). CAVI, Cardio Ankle Vascular Index; BMI, Body Mass Index

Baseline characteristics of this study are shown in Table 1. The mean of CAVI increased in age 30 to 69, was higher in male, uncontrolled diabetes and in active smoker (Fig. 2). Meanwhile, MHR distribution was higher in male and high BMI patients (Fig. 3).

Correlations of MHR with CAVI analysed by Spearman analysis were positive and significant correlations ( $\rho=0.239, p=0.031$ ) (Fig. 4). In addition, CAVI negatively correlated with the HDL cholesterol levels $(\rho=-0.284, p=0.01)$, but not with the monocyte count $(\rho=0.156, p=0.165)$. Univariate linear regression showed that age, body mass index, HbA1c, MHR, sex, smoking, hypertension, history of coronary artery disease, oral antidiabetic drugs and insulin had association with CAVI with $p$ value $<0.25$. Multivariate linear regression analysis revealed that all the variable values were associated with CAVI with $\mathrm{R}^{2}=0.422, p=0.000$. Partially, age, body mass index, HbA1c, MHR and smoking had an independent association with CAVI $(p<0.05)$ (Table 2). The results of this analysis revealed that there is an independent association of MHR with arterial stiffness, as measured by CAVI. 


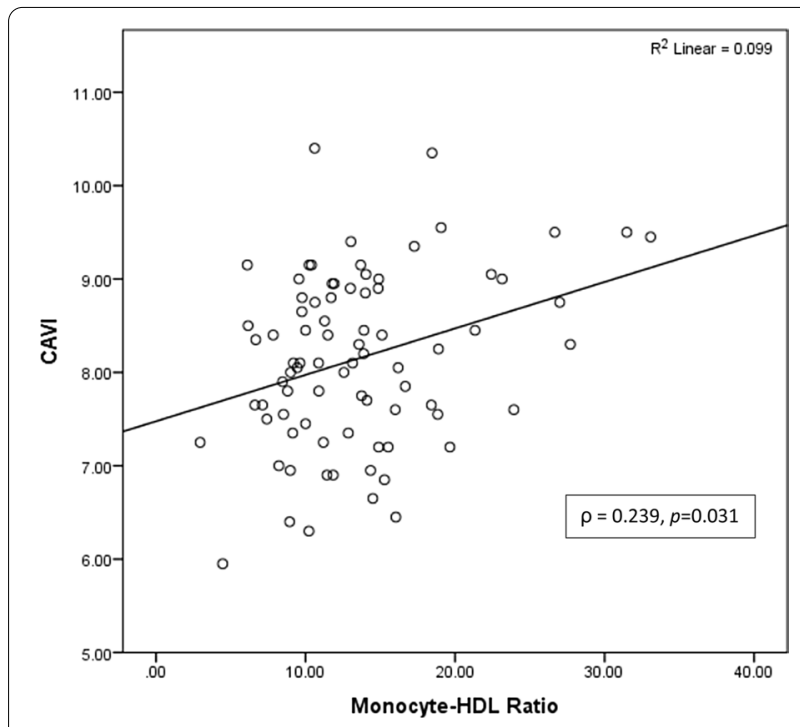

Fig. 4 Correlation of monocyte-to-HDL ratio with cardio ankle vascular index. HDL, High Density Lipoprotein

There was a significant difference between MHR distribution in CAVI $\geq 9$ and CAVI $<9(p=0.019)$ (Fig. 5). From multivariate logistic regression, MHR and HbA1c were independently associated with CAVI $\geq 9$ (Table 3 ). ROC curve analysis showed that the AUC of MHR was 0.687 (95\% CI 0.535-0.838) (Fig. 6). Monocyte-to-HDL ratio of $\geq 13$ (OR 3.289, 95\% CI 1036-10.441) had the best prediction cut-off value for CAVI $\geq 9$ with sensitivity of $70.6 \%$ and specificity of $59.4 \%$.

\section{Discussion}

In this pilot study, we found that there was a positive correlation of MHR with arterial stiffness, which was measured by CAVI in patients with diabetes. Furthermore, MHR may be used as a diagnostic tool for the prediction of $\mathrm{CAVI} \geq 9$. However, the power of this study is $75 \%$, which is considered underpowered. Therefore, further study with the larger sample size is needed.

There are only limited number of studies about arterial stiffness in Indonesia and this is the first study to observe the association of MHR with arterial stiffness, in which arterial stiffness is measured as CAVI using a VaSera machine. Arterial stiffness measurement by CAVI has some advantages such as it is independent of blood pressure at the time of measurement, has high reproducibility and sensitivity, and uses a user-friendly device with a simplified procedure [17]. CAVI is also an accurate predictor of cardiovascular events [18], and macrovascular complications such as peripheral artery disease in patients with diabetes who undergo dialysis [19]. CAVI that was used by this study is a combination of PWV and $\beta$ index, in which $\beta$ index assessed the stiffness only in one artery segment, but CAVI reflects the arterial stiffness of all arterial tree [20]. In the other study, there was a positive significant correlation between CAVI and $\beta$ index [21].

The association of MHR with CAVI in this study supports the previous finding that showed the positive and statistically significant correlation of MHR with arterial stiffness ( $\beta$ index) in patients with untreated hypertension and negative correlation of MHR with aortic

Table 2 Univariate and multivariate linear regression to predict arterial stiffness

\begin{tabular}{|c|c|c|c|c|c|c|}
\hline \multirow[t]{2}{*}{ Variables } & \multicolumn{3}{|c|}{ Univariate linear regression } & \multicolumn{3}{|c|}{ Multivariate linear regression } \\
\hline & Beta & $95 \% \mathrm{Cl}$ & $p$ value & Beta & $95 \% \mathrm{Cl}$ & $p$ value \\
\hline Age & 0.365 & 0.017 to 0.061 & 0.001 & 0.28 & 0.008 to 0.051 & $0.008^{*}$ \\
\hline DM duration & 0.098 & -0.017 to 0.043 & 0.384 & & & \\
\hline Monocyte-to-HDL ratio & 0.315 & 0.016 to 0.083 & 0.004 & 0.361 & 0.023 to 0.093 & $0.001^{*}$ \\
\hline BMl & -0.183 & -0.097 to 0.009 & 0.102 & -0.281 & -0.119 to $(-0.017)$ & $0.01^{*}$ \\
\hline $\mathrm{HbA1c}$ & 0.144 & -0.037 to 0.172 & 0.203 & 0.24 & 0.023 to 0.203 & $0.015^{*}$ \\
\hline LDL & -0.078 & -0.006 to 0.003 & 0.491 & & & \\
\hline Total cholesterol & 0.199 & -0.004 to 0.01 & 0.340 & & & \\
\hline Sex & 0.285 & 0.129 to 0.924 & 0.01 & 0.078 & -0.251 to 0.540 & 0.468 \\
\hline Smoking & 0.244 & 0.093 to 1.618 & 0.028 & 0.197 & 0.027 to 1.357 & $0.042^{*}$ \\
\hline Hypertension & 0.248 & 0.070 to 1.029 & 0.025 & 0.143 & -0.131 to 0.765 & 0.163 \\
\hline Coronary artery disease & 0.143 & -0.152 to 0.705 & 0.203 & -0.042 & -0.489 to 0.325 & 0.688 \\
\hline Statin & -0.078 & -0.564 to 0.271 & 0.486 & & & \\
\hline Vitamin & 0.028 & -0.361 to 0.462 & 0.807 & & & \\
\hline NSAID & 0.101 & -0.230 to 0.613 & 0.368 & & & \\
\hline ACE inhibitor/ARB & 0.012 & -0.394 to 0.437 & 0.918 & & & \\
\hline Oral antidiabetic drugs & 0.142 & -0.152 to 0.698 & 0.205 & 0.131 & -0.178 to 0.683 & 0.246 \\
\hline Insulin & -0.139 & -0.667 to 0.152 & 0.214 & -0.203 & -0.803 to 0.05 & 0.083 \\
\hline
\end{tabular}

${ }^{*} p<0.05$ was considered statistically significant 


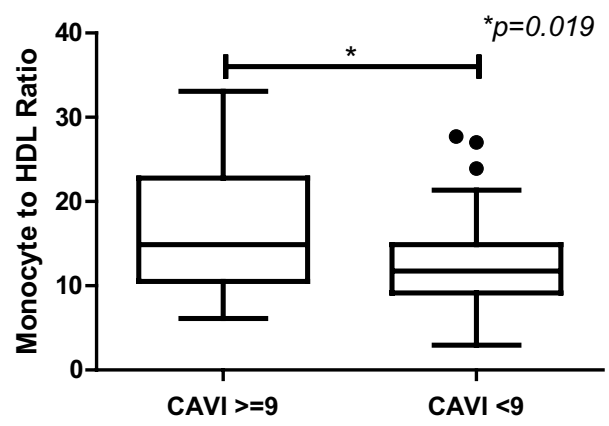

Fig. 5 Distribution of monocyte-to-HDL ratio in CAVI $\geq 9$ and $C A V I<9$. HDL, High Density Lipoprotein; CAVI, Cardio Ankle Vascular Index

distensibility [22]. Other significant finding in this study was the different distribution of $M H R$ in CAVI $\geq 9$ and CAVI $<9$. CAVI $\geq 9$ consist of higher number of $M H R$ than $\mathrm{CAVI}<9$. This result direct the chance that MHR associate with arterial stiffness, as measured by CAVI.

The independent relationship between MHR and CAVI showed the role of inflammation in the arterial stiffness process, as shown by monocytes' pro-inflammatory function and HDL anti-inflammatory properties. Interconnection between inflammatory pathways and various large artery stiffening mechanisms (degradation of elastin, calcification of medial, endothelial dysfunction) is mediated by increasing inflammatory cells. Inflammatory cascades lead to endothelial dysfunction promote vascular smooth muscle cells osteogenic differentiation and calcification [23]. Monocytes are the important elements of the inflammatory process. In a healthy community, monocyte count is a predictor of subclinical carotid atherosclerosis [24]. In diabetes, there would be an increase in pro-atherogenic monocyte activity such as IL- 6 and IL-1 $\beta$ production [25]. Another study revealed that there was an activation state of peripheral blood monocytes in diabetes with the increasing of CD36 and MCP-1 gene expressions [26]. Furthermore, in patients with diabetes, there is a strong polarization of monocytes caused by pro-inflammatory stimuli that promote the circulating monocytes into the activated M1 and M2 phenotypes [27]. Hyperglycaemia in diabetes will induce abnormal collagen production and elastin reduction that allows the formation of arterial stiffness [28]. Chronic inflammation also causes the decreasing of the number and function of HDL which will diminish its anti-inflammatory properties [29].

Monocyte-to-HDL ratio is a systemic inflammatory marker of various cardiovascular disorders. The MHR would be much higher in patients with type 2 diabetes

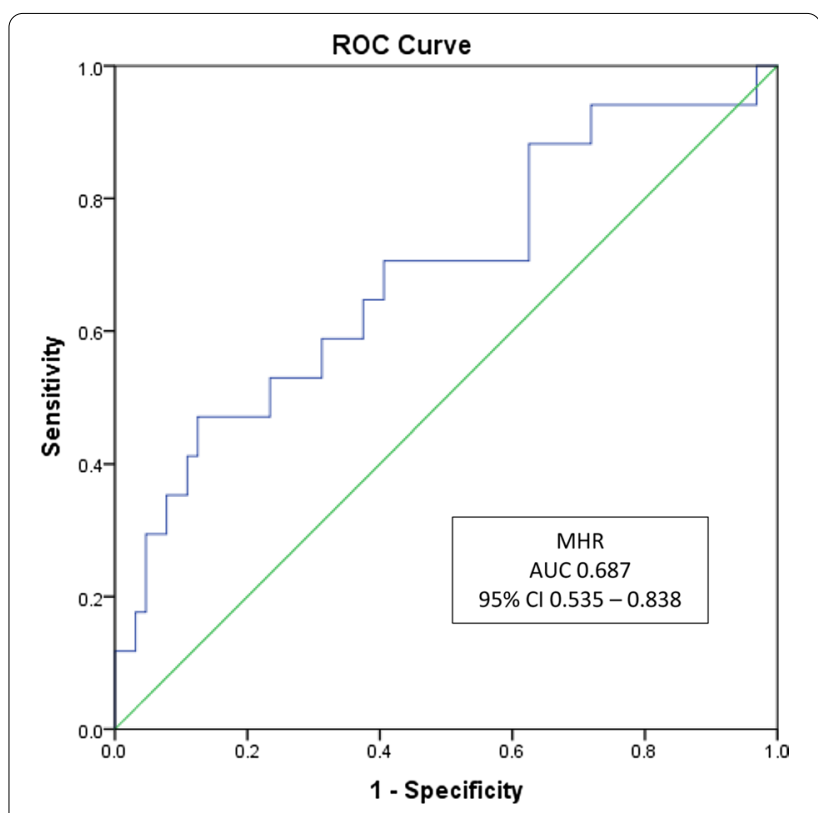

Fig. 6 ROC curve analysis and AUC of MHR for prediction of $C A V I \geq 9$. AUC, Area under curve; HDL, High Density Lipoprotein; CAVI, Cardio Ankle Vascular Index; MHR,Monocyte-to-HDL Ratio

[30] and metabolic syndrome [31, 32]. The higher MHR in patients with diabetes was supported by the increase of monocyte [33] and the decrease of HDL levels compared to non-diabetic patients [34, 35]. Arterial stiffness and MHR may be linked by a subclinical inflammation in the vessel wall. The increasing of white blood cell counts, including the monocyte count, had a dose-dependent association with brachial-ankle pulse wave velocity tertiles in patients with type 2 diabetes mellitus in China [36]. On the other side, HDL had a negative correlation with CAVI in hypertension patients [37] and with abdominal aortic stiffness assessed by $\beta$ stiffness index in subjects with varying insulin sensitivity [38].

Inflammation and lipid abnormality are main factors in the development of atherosclerosis, have role in healing response to vascular injury and allow the initiation and growth of atherosclerotic plaque [39]. Increasing of arterial stiffness is an indicator of atherosclerosis process in the vessel wall, and this arterial stiffness has a high predictive value in the future cardiovascular events [40]. Previous study showed an association of baPWV and augmentation index with inflammatory markers, such as CRP, tumor necrosis factor-alpha (TNF- $\alpha$ ) and Interleukin-6 (IL-6) in hypertension patients [41] and CRP in healthy individuals [42].

Other earlier studies observed the correlation of MHR with hs-CRP and found it was associated with slow coronary flow events of stable angina pectoris with normal coronary arteries by angiography [43]. Other study 
Table 3 Univariate and multivariate logistic regression predict $C A V I \geq 9$

\begin{tabular}{|c|c|c|c|c|c|c|}
\hline \multirow[t]{2}{*}{ Variables } & \multicolumn{3}{|c|}{ Univariate logistic regression } & \multicolumn{3}{|c|}{ Multivariate logistic regression } \\
\hline & OR & $95 \% \mathrm{Cl}$ & $p$ value & OR & $95 \% \mathrm{Cl}$ & $p$ value \\
\hline Age & 1.063 & $0.991-1.140$ & 0.087 & 1.074 & $0.983-1.172$ & 0.112 \\
\hline DM duration & 1.003 & $0.928-1.084$ & 0.944 & & & \\
\hline Monocyte-to-HDL ratio & 1.138 & $1.037-1.248$ & 0.006 & 1.181 & $1.047-1.332$ & $0.007^{*}$ \\
\hline BMI & 0.973 & $0.843-1.123$ & 0.705 & & & \\
\hline $\mathrm{HbA1c}$ & 1.292 & $0.981-1.702$ & 0.069 & 1.515 & $1.044-2.199$ & $0.029^{*}$ \\
\hline LDL & 1.003 & $0.991-1.016$ & 0.589 & & & \\
\hline Total cholesterol & 1.010 & $0.992-1.028$ & 0.296 & & & \\
\hline Sex & 0.444 & $0.140-1.405$ & 0.167 & 0.855 & $0.189-3.873$ & 0.855 \\
\hline Smoking & 4.357 & $0.794-23.909$ & 0.09 & 4.717 & $0.657-33.852$ & 0.123 \\
\hline Hypertension & 1.429 & $0.361-5.648$ & 0.611 & & & \\
\hline Coronary artery disease & 1.041 & $0.340-3.193$ & 0.944 & & & \\
\hline Statin & 0.977 & $0.330-2.899$ & 0.967 & & & \\
\hline Vitamin & 1.198 & $0.410-3.495$ & 0.741 & & & \\
\hline NSAID & 1.167 & $0.392-3.471$ & 0.782 & & & \\
\hline ACE inhibitor/ARB & 0.608 & $0.208-1.782$ & 0.365 & & & \\
\hline Oral antidiabetic drugs & 1.44 & $0.452-4.591$ & 0.538 & & & \\
\hline Insulin & 0.691 & $0.236-2.021$ & 0.5 & & & \\
\hline
\end{tabular}

${ }^{*} p<0.05$ was considered statistically significant

observed that MHR positively correlates to CRP, Gensini score and SYNTAX score in patients with acute coronary syndrome. Furthermore, MHR in third tertile group is an independent predictor to cardiovascular events during hospitalization and long term follow-up [44, 45]. Meanwhile in patients with diabetes, MHR was also correlated with carotid intimal-media thickness [30] and strongly associated with coronary artery disease in type 2 DM [46].

Some limitations of this study included the small number of the samples which limited the significance of the findings. The ROC analysis to define the cut-off was still based on the cross-sectional study for piloting the study. Further study with a cohort prospective design is needed. Besides, in this study there were no other inflammation markers examined such as CRP, IL- 6 and TNF- $\alpha$ which can be used to confirm the role of MHR in arterial stiffness.

\section{Conclusion}

Our findings indicate that MHR is associated with arterial stiffness in diabetic patients, irrespective of various potential confounders. A cut-off $M H R \geq 13$ may predicts the CAVI $\geq 9$. Future study is needed to observe the benefit of MHR measurement in the prediction of arterial stiffness in patients with diabetes.

\section{Abbreviations}

HDL: High density lipoprotein; MHR: Monocyte-to-HDL ratio; CAVI: Cardio ankle vascular index; DM: Diabetes melitus; NO: Nitrite oxide; eNOS: endothelial NO synthase; LDL: Low density lipoprotein; ABI: Ankle brachial index; eGFR: estimated Glomerular filtration rate; SD: Standard deviation; IQR: Interquartile range; AUC: Area under curve; PWV: Pulse wave velocity; baPWV: Brachial ankle pulse wave velocity; IL-1 $\beta$ : Interleukin-1 beta; IL-6: Interleukin-6; MCP-1: Monocyte chemoattractant protein-1; CRP: C-reactive protein; TNF-a: Tumor necrosis factor-alpha.

\section{Acknowledgements}

We would like to thank all the clinicians involved in this study at Dr. Sardjito General Hospital Yogyakarta Indonesia

\section{Authors' contributions}

DSM participated in the design of study, performed data collection, data analysis, and wrote and edited the manuscript, NT participated in the design of study, analysis of results and manuscript review, $\mathrm{HH}$ participated in the design of study, interpretation of results, and manuscript review. All authors read and approved the final manuscript.

\section{Funding}

This research received no external funding.

\section{Availability of data and materials}

The data of this study may be available on reasonable request to the corresponding author.

\section{Declarations}

\section{Ethics approval and consent to participate}

This study was approved by the Medical and Health Research Ethics Committee (MHREC) Faculty of Medicine, Public Health and Nursing, Universitas Gadjah Mada-Dr. Sardjito General Hospital, Indonesia. Each subject received the information and signed the consent to participate in accordance with principles of the Declaration of Helsinki. 


\section{Consent for publication}

Not applicable.

\section{Competing interests}

The authors declare that they have no competing interests.

\section{Author details}

${ }^{1}$ Department of Cardiology and Vascular Medicine, Public Health and Nursing, Faculty of Medicine, Universitas Gadjah Mada, JI Farmako No 1, Sekip, Yogyakarta 55281, Indonesia. ${ }^{2}$ Dr. Sardjito General Hospital, Yogyakarta, Indonesia.

Received: 8 April 2021 Accepted: 23 July 2021

Published online: 30 July 2021

\section{References}

1. Paneni F, Beckman JA, Creager MA, Cosentino F. Diabetes and vascular disease: pathophysiology, clinical consequences, and medical therapy: part I. Eur Heart J. 2013;34:2436-43. https://doi.org/10.1093/eurheartj/ eht149.

2. Rask-Madsen C, King GL. Vascular complications of diabetes: mechanisms of injury and protective factors. Cell Metab. 2013;17:20-33. https://doi. org/10.1016/j.cmet.2012.11.012

3. Elias MF, Crichton GE, Dearborn PJ, Robbins MA, Abhayaratna WP. Associations between type 2 diabetes mellitus and arterial stiffness: a prospective analysis based on the maine-syracuse study. Pulse. 2017;5:88-98. https://doi.org/10.1159/000479560.

4. Loehr LR, Meyer ML, Poon AK, Selvin E, Palta P, Tanaka H, et al. Prediabetes and diabetes are associated with arterial stiffness in older adults: the ARIC study. Am J Hypertens. 2016;29:1038-45.

5. Zieman SJ, Melenovsky V, Kass DA. Mechanisms, pathophysiology, and therapy of arterial stiffness. Arter Thromb Vasc Biol. 2005;25:932-43.

6. Mattace-Raso FUS, van der Cammen TJM, Hofman A, Van PNM, Bos ML, Schalekamp MADH, et al. Arterial stiffness and risk of coronary heart disease the rotterdam study. Circulation. 2006;113:657-63.

7. Kim JM, Kim SS, Kim IJ, Kim JH, Kim BH, Kim MK, et al. Arterial stiffness is an independent predictor for risk of mortality in patients with type 2 diabetes mellitus: the REBOUND study. Cardiovasc Diabetol. 2020;19:143. https://doi.org/10.1186/s12933-020-01120-6.

8. Yiu K-H, Zhao C-T, Chen Y, Siu C-W, Chan Y-H, Lau K-K, et al. Association of subclinical myocardial injury with arterial stiffness in patients with type 2 diabetes mellitus. Cardiovasc Diabetol. 2013;12:94. https://doi.org/10. 1186/1475-2840-12-94.

9. Greene SJ, Harinstein ME, Vaduganathan M, Subačius $H$, Konstam MA, Zannad $\mathrm{F}$, et al. Prognostic value of monocyte count in patients hospitalized for heart failure with reduced ejection fraction (from the EVEREST Trial). Am J Cardiol. 2012;110:1657-62.

10. Hu J, Xi D, Zhao J, Luo T, Liu J, Lu H, et al. High-density Lipoprotein and inflammation and its significance to atherosclerosis. Am J Med Sci. 2016:352:408-15.

11. Lüscher TF, Landmesser U, Von EA, Fogelman AM. High-density lipoprotein: vascular protective effects, dysfunction, and potential as therapeutic target. Circ Res. 2014;114:171-82.

12. Gembillo G, Siligato R, Cernaro V, Satta E, Conti G, Salvo A, et al. Monocyte to HDL ratio: a novel marker of resistant hypertension in CKD patients. Int Urol Nephrol. 2021. https://doi.org/10.1007/s11255-021-02904-9.

13. Karatas A, Turkmen E, Erdem E, Dugeroglu H, Kaya Y. Monocyte to highdensity lipoprotein cholesterol ratio in patients with diabetes mellitus and diabetic nephropathy. Biomark Med. 2018;12:953-9. https://doi.org/ 10.2217/bmm-2018-0048.

14. Cannon CP, Brindis RG, Chaitman BR, Cohen DJ, Cross JT, Drozda JP, et al. 2013 ACCF/AHA Key data elements and definitions for measuring the clinical management and outcomes of patients with acute coronary syndromes and coronary artery disease: a report of the American college of cardiology foundation/American Heart Association. Circulation. 2013;127:1052-89.

15. Stone NJ, Jennifer GR, Lichtenstein AH, Merz CNB, Blum CB, Eckel RH, et al. 2013 ACC/AHA guideline on the treatment of blood cholesterol to reduce atherosclerotic cardiovascular risk in adults. Circulation.
2014;129(25_suppl_2):S1-45. https://doi.org/10.1161/01.cir.0000437738. 63853.7a.

16. Chung S-L, Yang C-C, Chen C-C, Hsu Y-C, Lei M-H. Coronary artery calcium score compared with cardio-ankle vascular index in the prediction of cardiovascular events in asymptomatic patients with type 2 diabetes. J Atheroscler Thromb. 2015;22:1255-65.

17. Asmar R. Principles and usefulness of the cardio-ankle vascular index (CAVI): a new global arterial stiffness index. Eur Hear J Suppl. 2017;19(Supplement B):B4-10.

18. Kubota Y, Maebuchi D, Takei M, Inui Y, Sudo Y, Ikegami Y, et al. Cardioankle vascular index is a predictor of cardiovascular events. Artery Res. 2011;5:91-6. https://doi.org/10.1016/j.artres.2011.03.005.

19. Furuya F, Motosugi A, Haraguchi K, Hanai S, Ishii T, Yamaguchi Y, et al. Association between the cardio-ankle vascular index and diabetes mellitus-related peripheral arterial disease in chronic hemodialysis patients. Blood Purif. 2019;47(suppl 2):1-6.

20. Hayashi K, Yamamoto T, Takahara A, Shirai K. Clinical assessment ofarterial stiffness with cardio-ankle vascular index: theory and applications. J Hypertens. 2015;33:1742-57.

21. Takaki A, Ogawa H, Wakeyama T, Iwami T, Kimura M, Hadano Y, et al. Cardio-ankle vascular index is a new noninvasive parameter of arterial stiffness. Circ J. 2007;71:1710-4.

22. Yayla KG, Canpolat U, Yayla Ç, Akboga MK, Akyel A, Akdi A, et al. A novel marker of impaired aortic elasticity in never treated hypertensive patients: monocyte/high-density lipoprotein cholesterol ratio. Acta Cardiol Sin. 2017;33:41-9.

23. Chirinos JA, Segers $P$, Hughes $T$, Townsend R. Large-artery stiffness in health and disease: JACC state-of-the-art review. J Am College Cardiol. 2019;74:1237-63.

24. Chapman CML, Beilby JP, McQuillan BM, Thompson PL, Hung J. Monocyte count, but not c-reactive protein or interleukin-6, is an independent risk marker for subclinical carotid atherosclerosis. Stroke. 2004;35:1619-24. https://doi.org/10.1161/01.STR.0000130857.19423. ad.

25. Devaraj S, Jialal I. Low-density lipoprotein postsecretory modification, monocyte function, and circulating adhesion molecules in type 2 diabetic patients with and without macrovascular complications. Circulation. 2000;102:191-6. https://doi.org/10.1161/01.CIR.102.2.191.

26. Cipolletta C, Ryan KE, Hanna EV, Trimble ER. Activation of peripheral blood CD14+ monocytes occurs in diabetes. Diabetes. 2005;54:2779-86

27. Nikiforov NG, Galstyan KO, Nedosugova LV, Elizova NV, Kolmychkova KI, Ivanova EA. Proinflammatory monocyte polarization in type 2 diabetes mellitus and coronary heart disease. Vessel Plus. 2017;1:192-5.

28. Prenner SB, Chirinos JA. Arterial stiffness in diabetes mellitus. Atherosclerosis. 2015;238:370-9. https://doi.org/10.1016/j.atherosclerosis.2014.12. 023.

29. Chiesa ST, Charakida M. High-density lipoprotein function and dysfunction in health and disease. Cardiovasc Drugs Ther. 2019;33:207-19. https://doi.org/10.1007/s10557-018-06846-w.

30. Chen JW, Li C, Liu ZH, Shen Y, Ding FH, Shu XY, et al. The role of monocyte to high-density lipoprotein cholesterol ratio in prediction of carotid intima-media thickness in patients with type 2 diabetes. Front Endocrinol (Lausanne). 2019;10:1-11.

31. Uslu AU, Sekin Y, Tarhan G, Canakcı N, Gunduz M, Karagulle M. Evaluation of monocyte to high-density lipoprotein cholesterol ratio in the presence and severity of metabolic syndrome. Clin Appl Thromb. 2018;24:828-33.

32. Vahit D, Akboga MK, Samet $Y$, Hüseyin E. Assessment of monocyte to high density lipoprotein cholesterol ratio and lymphocyte-to-monocyte ratio in patients with metabolic syndrome. Biomark Med. 2017;11:535-40. https://doi.org/10.2217/bmm-2016-0380.

33. Min D, Brooks B, Wong J, Salomon R, Bao W, Harrisberg B, et al. Alterations in monocyte CD16 in association with diabetes complications. Mediators Inflamm. 2012;2012: 649083. https://doi.org/10.1155/2012/649083.

34. Gordon SM, Davidson WS, Urbina EM, Dolan LM, Heink A, Zang H, et al. The effects of type 2 diabetes on lipoprotein composition and arterial stiffness in male youth. Diabetes. 2013;62:2958-67.

35. Mooradian AD. Dyslipidemia in type 2 diabetes mellitus. Nat Clin Pract Endocrinol Metab. 2009;5:150-9.

36. Liu Y, Lai X, Guo W, Ma L, Li W, Fang Q, et al. Total white blood cell count mediated the association between increased arterial stiffness and risk of 
type 2 diabetes mellitus in chinese adults. Arterioscler Thromb Vasc Biol. 2020;40:1009-15. https://doi.org/10.1161/ATVBAHA.119.313880.

37. Wang H, Liu J, Zhao H, Zhao X, Li L, Shi H, et al. Relationship between cardio-ankle vascular index and plasma lipids in hypertension subjects. J Hum Hypertens. 2015;29:105-8.

38. Gottsäter M, Länne T, Nilsson PM. Predictive markers of abdominal aortic stiffness measured by echo-tracking in subjects with varying insulin sensitivity. J Hum Hypertens. 2014;28:456-60.

39. Wang H, Shi W, Yi X, Zhou Y, Wang Z, Sun Y. Assessing the performance of monocyte to high-density lipoprotein ratio for predicting ischemic stroke: insights from a population- based Chinese cohort. Lipids Health Disease. 2019;18:1-11.

40. Çakar M, Balta Ş, Şarlak H, Akhan M, Demirkol S, Karaman M, et al. Arterial stiffness and endothelial inflammation in prediabetes and newly diagnosed diabetes patients. Arch Endocrinol Metab. 2015;59:407-13.

41. Mahmud A, Feely J. Arterial stiffness is related to systemic inflammation in essential hypertension. Hypertension. 2005;46:1118-22.

42. Yasmin MECM, Wallace S, Mackenzie IS, Cockcroft JR, Wilkinson IB. C-reactive protein is associated with arterial stiffness in apparently healthy individuals. Arterioscler Thromb Vasc Biol. 2004;24:969-74. https://doi. org/10.1161/01.ATV.zhq0504.0173.

43. Canpolat U, Çetin EH, Cetin S, Aydin S, Akboga MK, Yayla C, et al. Association of monocyte-to-HDL cholesterol ratio with slow coronary flow association of monocyte-to-HDL cholesterol ratio with slow coronary flow is linked to systemic inflammation. Clin Appl Thromb. 2015;22:1-7.

44. Cetin MS, Hande E, Cetin O. Monocyte to HDL cholesterol ratio predicts coronary artery disease severity and future major cardiovascular adverse events in acute coronary syndrome. Heart Lung Circ. 2016;25:1077-86. https://doi.org/10.1016/j.hlc.2016.02.023.

45. Villanueva DLE, Tiongson MD, Ramos JD, Llanes EJ. Monocyte to highdensity lipoprotein ratio (MHR) as a predictor of mortality and major adverse cardiovascular events (MACE) among ST elevation myocardial infarction (STEMI) patients undergoing primary percutaneous coronary intervention: a meta-analysis. Lipids Health Dis. 2020;19:55. https://doi. org/10.1186/s12944-020-01242-6.

46. Ya G, Qiu Z, Tianrong P. Relation of monocyte/high-density lipoprotein cholesterol ratio with coronary artery disease in type 2 diabetes mellitus. Clin Lab. 2018;64:901-6.

\section{Publisher's Note}

Springer Nature remains neutral with regard to jurisdictional claims in published maps and institutional affiliations.
Ready to submit your research? Choose BMC and benefit from:

- fast, convenient online submission

- thorough peer review by experienced researchers in your field

- rapid publication on acceptance

- support for research data, including large and complex data types

- gold Open Access which fosters wider collaboration and increased citations

- maximum visibility for your research: over $100 \mathrm{M}$ website views per year

At BMC, research is always in progress.

Learn more biomedcentral.com/submissions 